\title{
FABRICAÇÃO DE DOCE DE GOIABA COM APROVEITAMENTO DO ALBEDO DO MARACUJÁ AMARELO
}

\author{
Lúcia C. Carneiro \\ Professora do IFRN - Campus Currais Novos. E-mail: luciacesarcarneiro@yahoo.com.br
}

Allyne Mayara de M. Bezerra

Técnica em Alimentos - IFRN - Campus Currais Novos.

E-mail: allyne.mayara@hotmail.com

Jolian Alex de M. GUEDES

Aluno do Curso Técnico Subsequente em Alimentos. Bolsista de IC do IFRN - Campus

Currais Novos. E-mail: jolianmedeiros@hotmail.com

\section{RESUMO}

Atualmente é crescente a busca por produtos derivados de frutas mistas, com ênfase em espécies vegetais que reúnem boas características nutricionais, sensoriais e propriedades funcionais. A goiaba vermelha é uma boa fonte de vitamina C, licopeno e fibra solúvel. Estas substâncias têm sido associadas com a prevenção da formação de radicais livres pelo organismo, doenças cardiovasculares, diabete, alguns tipos de câncer, entre outras enfermidades. No processamento industrial do maracujá visando à obtenção de polpas e sucos são gerados muitos resíduos. As cascas representam em média 61,9\% do peso do fruto; são ricas em carboidratos e apresentam considerável teor de pectina, em média 20\% na base seca. A pectina é uma fibra solúvel de grande importância para a saúde. Na elaboração de doces e geléias de frutas, constitui um ingrediente necessário à formação de gel e melhoria de textura. O produto comercial, extraído do resíduo das frutas cítricas requer processo tecnológico sofisticado e por isso, tem custo elevado, o que dificulta a sua aquisição e uso pelas pequenas agroindústrias familiares. O doce misto de goiaba com aproveitamento do albedo do maracujá vai de encontro às necessidades de pequenos produtores de doces e às exigências do mercado consumidor, além de contribuir para o melhor aproveitamento das matérias primas agropecuárias. O objetivo deste trabalho foi testar diferentes concentrações de albedo do maracujá amarelo visando a obtenção de um doce em massa "tipo corte" sem adição de pectina comercial e compará-lo sensorialmente com uma goiabada comercial. Foram testadas duas formulações de doces em massa tipo corte, diferindo quanto à concentração de polpa de goiaba albedo e utilizados, uma com $70 \%$ e $30 \%$ (F1) e outra com $60 \%$ e $40 \%$. As misturas foram acrescidas de açúcar e ácido cítrico como ajustador de $\mathrm{pH}$, sendo concentradas até atingir teores de sólidos solúveis ( ${ }^{\circ}$ Brix) igual a $71.00 \%$ (F1) e $72.00 \%$ (F2). Os doces obtidos foram acondicionados em postes de plástico atóxico, de cor branca, previamente sanitizados e secos. Realizou-se a determinação do $\mathrm{pH}$, sólidos solúveis totais ( ${ }^{\circ}$ Brix), acidez e umidade. Seguindo as normas analíticas do Instituto Adolfo Lutz (1985). Sensorialmente foram avaliados quanto à aparência, cor, textura e sabor, utilizando-se uma escala hedônica de nove pontos. De acordo com o teste de médias, em relação à cor e sabor, a amostra comercial obteve maior aceitabilidade, seguida da F2, com menor concentração de albedo.

Palavras chave: goiaba, albedo do maracujá, Brix, $\mathrm{pH}$, análise sensorial. 


\section{FABRICAÇÃO DE DOCE DE GOIABA COM APROVEITAMENTO DO ALBEDO DO MARACUJÁ AMARELO}

\section{1- INTRODUÇÃO}

A goiaba (Psidium guiavvva L.) é uma fruta nativa da América tropical e atualmente pode ser encontrada em todas as regiões do Brasil. Sua produção em escala industrial no país teve início na década de 70, quando grandes áreas tecnificadas foram implantadas, com produção direcionada para os mercados nacional e internacional, na forma in natura, industrializada (doces e sucos) e desidratada (CHOUDHURY et al.,2001).

O Brasil é considerado um dos maiores produtores de goiaba em termos mundiais, com um volume de cerca de 345.533 mil toneladas em 2005, obtidas em 16.399 mil ha (FAO2006).

Dentre as frutas tradicionais, a goiaba destaca-se pela grande aceitação na sua forma in natura e para o consumo na indústria sob múltiplas formas; pelo seu valor nutritivo como excelente fonte de vitamina C, cerca de 61,0 a $96,0 \mathrm{mg} / 100 \mathrm{~g}$ para a goiaba vermelha e 60,0 a $64,0 \mathrm{mg} / 100 \mathrm{~g}$ de polpa para a goiaba branca (ARANHA E SIMÕES, 2003), pela fonte de licopeno; de fibra solúvel, a pectina (EMBRAPA, 2003). Estas substâncias têm sido associadas com a prevenção de várias doenças.

Fruta tropical abundante em todo o país, o maracujá é muito apreciado, tendo lugar cativo em diversas preparações culinárias, e, sobretudo, na industrialização de polpa e suco. No processamento industrial visando à obtenção de polpas e sucos são gerados muitos resíduos, como a mucilagem obtida após centrifugação, as sementes (11\%) e as cascas, que representa em média 61,9\% do peso do fruto. As cascas do maracujá contêm carboidratos, são fontes regulares de proteína, material mineral, fibras insolúvel (celulose) e solúvel (pectina), em média $20 \%$ na base seca (TOCCHINI et. al. 1995). A pectina é responsável pela consistência das geléias e doces juntamente com o ácido e açúcares. Também tem ampla aplicação em produtos farmacêuticos.

As cascas do maracujá, comumente destinadas à produção de ração animal; nos últimos anos têm despertado interesse de inúmeros pesquisadores, no desenvolvimento de produtos destinados à alimentação humana, como barras de cereais (URBANO, 2003), doce em calda (COSTA, et al, 2008), geléias e doces em massa (CARNEIRO, et. al. 2004 e 2005).

Nas últimas décadas é cada vez maior a procura por produtos à base de frutas, devido, principalmente, à presença de vitaminas A e C, e de fibras, que, por sua vez, têm sido associadas à prevenção de doenças como o câncer, distúrbios coronários e excesso de colesterol. Paralelamente, observa-se uma forte tendência da indústria alimentícia brasileira pela elaboração de produtos derivados de frutas, formulados com várias misturas de frutas e até hortaliças, como os néctares de laranja com cenoura e mamão, laranja e cenoura, manga com maracujá, entre outros, com a finalidade de enriquecimento nutricional e a oferta de produtos exóticos e atrativos que atendam a gastronomia moderna.

Considerando o sabor pronunciado da goiaba, o grande desperdício das cascas do maracujá e sua fonte natural de pectina, em média $20 \%$ de sua matéria seca a combinação do albedo do maracujá com a polpa de goiaba poderá constituir uma alternativa tecnológica à 
produção de doce de misto com valor nutricional diferenciado dos já existentes no mercado, com baixo custo e acessível às pequenas agroindústrias familiares.

Pelo exposto, o presente trabalho teve por objetivo testar a utilização de diferentes concentrações de polpa de goiaba e do albedo do maracujá amarelo, visando a obtenção de um doce em massa "tipo corte" sem adição de pectina comercial e compará-lo sensorialmente com uma goiabada comercial.

\section{2- REVISÃO BIBLIOGRÁFICA}

De acordo com a Resolução Normativa CTA n. 9/78, doce em pasta ou massa é o produto resultante do processamento adequado das partes comestíveis desintegradas de vegetais com açúcares, com ou sem adição de água, pectina, ajustador de $\mathrm{pH}$ e outros ingredientes e aditivos permitidos pela legislação de alimentos, até a consistência apropriada, sendo, finalmente acondicionado de forma a assegurar sua perfeita conservação” (JACKIX, 1988; EMBRAPA, 2003).

Dependendo da consistência, os doces em massa podem ser designados "doce cremoso ou pastoso" e "doce de corte", podendo ser classificado em doce simples, quando preparado com um tipo de polpa e doce misto, quando fabricado com mais de um tipo de polpa. $\mathrm{O}$ processamento é semelhante, diferindo basicamente nas proporções de alguns ingredientes e na concentração de sólidos solúveis ( ${ }^{\circ}$ Brix) no produto final.

A goiabada, bananada, pessegada são os doces mais populares em diferentes regiões do país, sendo consumida naturalmente ou utilizadas com ingredientes na elaboração de churros e produtos de panificação.

Os doces de massa de goiaba, nas diferentes regiões do país, são conhecidos como goiabada; pode apresentar consistência mole (doce cremoso) e consistência mais dura (doce de corte), que geralmente é cortado em pequenos tabletes ou é acondicionado em embalagens de plásticas flexíveis ou lata.

Para a produção de goiabada utiliza-se a polpa de goiaba, açúcar, pectina e ácido cítrico. O doce em massa, também conhecido como goiabada pode apresentar consistência mole (doce cremoso) e consistência mais dura (doce de corte), que geralmente é cortado em pequenos tabletes ou é acondicionado em embalagens de plásticas flexíveis ou lata.

Os doces em massa podem ser obtidos Para produção de goiabada utiliza-se a polpa de goiaba, açúcar, pectina e ácido cítrico.

Recomendam que para a fabricação de doce em massa de goiaba, o cozimento da polpa deve ser realizado até atingir teor de sólidos solúveis de 65 Brix, para obtenção de textura adequada após o resfriamento. Para o doce de corte pose-se adicionar pedaços de goiaba, denominando-se goiabadas cascão. O produto deve ser concentrado até que o ${ }^{\circ}$ Brix atinja valor suficiente para que ocorra a geleificação durante o resfriamento e o ponto de corte (JACKIX, 1988). 


\section{3- METODOLOGIA}

\subsection{Matérias-prima utilizadas}

As polpas de frutas e cascas do maracujá foram provenientes de uma unidade de processamento de polpa de frutas pertencente à Associação Clube de Mães e Jovens Tereza Celestina Dantas, localizada no Povoado Cruz, município de Currais Novos.

\subsection{Processo de obtenção dos doces}

A polpa de goiaba (Psidium guiavvva $L$ ) congelada e as cascas do maracujá foram conduzidas ao Laboratório de Alimentos do Instituto Federal de Educação Tecnológica do Estado do Rio Grande do Norte, onde o presente estudo foi realizado. As cascas do maracujá amarelo (Passiflora war edulis Flavicarp) foram cozidas e resfriadas em água corrente para facilitar a extração da polpa branca carnuda, também conhecida como albedo. Este foi misturado com água na proporção 1:1, homogeneizado em liquidificador, até atingir um aspecto de pasta. Foram elaboradas, a partir das polpas de goiaba e do albedo do maracujá duas formulações de doce misto tipo corte, nas seguintes proporções: 30 e $70 \%$ (F1) e 40 e $60 \%$ (F2). Adicionou-se $70 \%$ de sacarose para ambas as formulações. As misturas foram concentradas em panela de aço inoxidável até que atingisse o teor de sólidos solúveis em tono de $76{ }^{\circ}$ Brix. Para ajustar o $\mathrm{pH}$ para valores adequados à geleificação, entre 3,0 e 3,3 adicionou acido cítrico. Os doces foram acondicionados em potes de plástico atóxico de cor branca, sanitizados e secos.

\subsection{Caracterização físico-química}

Foi determinada realizando-se análises em triplicata dos teores de sólidos solúveis ( ${ }^{\circ}$ Brix) utilizando refratômetro de bancada, após sua calibração. As amostras foram diluídas, utilizando-se a relação 1:2. Os resultados foram corrigidos em função da diluição e temperatura das amostras. $\mathrm{O} \mathrm{pH}$ foi obtido através da leitura direta em $\mathrm{pH}$-metro de bancada devidamente calibrado. A acidez total titulável, utilizando solução de $\mathrm{NaOH} 0,1 \mathrm{~N}$, e solução fenolftaleína com indicador, sendo os resultados expressos em (\%p/p) de ácido cítrico. A umidade, através de estufa regulada a $75^{\circ} \mathrm{C}$. Estes procedimentos seguram as normas analíticas do Instituto Adolfo Lutz, (1985).

\subsection{Avaliação sensorial}

O estudo de aceitabilidade foi realizado no IFRN, campus de Currais Novos com provadores não treinados de ambos os sexos. As amostras foram servidas em copos descartáveis de cor branca, codificadas com três algarismos aleatórios, contendo $\pm 25 \mathrm{~g}$ de doce. Utilizou-se escala hedônica estruturada de nove pontos ( 1 = desgostei extremamente; 5 = nem gostei/nem desgostei; 9 = gostei extremamente) para avaliar o produto quanto aos atributos cor, sabor, textura e aparência, comparando-se estes atributos com um produto comercial. Os resultados foram submetidos à análise de variância (ANOVA), seguida de teste de Tukey $(\mathrm{p}<0,05)$. 


\section{ANÁLISE E INTERPRETAÇÃO DOS DADOS}

\subsection{Caracterização físico-química de doce misto formulado com diferentes} concentrações de polpa de goiaba e albedo do maracujá

Pelos dados apresentados na Tabela 1 verifica-se que os teores de sólidos solúveis estão de acordo com os valores de referências encontrados na literatura (JACKIX, 1988; EMBRAPA, 2003). Em relação ao pH e acidez constata-se que será necessário adicionar mais ácido as formulações para que se possam atingir os valores de referências, que é de 0,5 a $0,8 \%$ para a acidez e pH em torno de 3,2 (EMBRAPA, 2003).

Tabela 1: Resultados de alguns parâmetros físico-químicos dos doces de goiaba.

\begin{tabular}{|c|c|c|c|}
\hline Amostras & \multicolumn{3}{|c|}{ *Parâmetros físico-químicos } \\
\hline & $\begin{array}{c}\text { Sólidos Solúveis } \\
\left({ }^{\circ} \text { BRIX) }\right.\end{array}$ & pH & $\begin{array}{c}\text { Acidez em ácido } \\
\text { cítrico (\%) }\end{array}$ \\
\hline F1 & 70,83 & 4,09 & 0,56 \\
\hline F2 & 71,68 & 4,01 & 0,39 \\
\hline
\end{tabular}

*Valores médios obtido de três repetições.

4.2. Aceitação sensorial de doce misto formulado com diferentes concentrações de polpa de goiaba e albedo do maracujá, em comparação com uma goiabada comercial.

Na (tabela 2) estão apresentados resultados obtidos da avaliação sensorial dos doces de goiaba, onde verifica-se pequenas diferenças entre as amostras estudadas.

Em relação a cor e sabor, a amostra comercial obteve maior aceitabilidade, seguida da amostra contendo a menor concentração de albedo. Em termos de aparência não foi constatada diferença significativa. Para a textura, verifica-se que a amostra comercial também obteve a maior preferência, no entanto, não foi constatado diferença em relação à concentração de albedo utilizada nas diferentes formulações.

De acordo com os resultados obtidos na análise sensorial através da análise de variância e teste de média, verificou-se que:

Tabela 2: Média das notas para cada um dos atributos e seus DMS*

\begin{tabular}{|c|c|c|c|c|}
\hline Formulações & Cor & Aparência & Textura & Sabor \\
\hline F1 & $6,45 \mathrm{~b}$ & 7,25 & $7,53 \mathrm{~b}$ & $6,23 \mathrm{~b}$ \\
\hline F2 & $7,25 \mathrm{c}$ & 7,45 & $7,50 \mathrm{~b}$ & $6,60 \mathrm{c}$ \\
\hline $\begin{array}{c}\text { Produto } \\
\text { comercial }\end{array}$ & $7,78 \mathrm{a}$ & 7,33 & $6,55 \mathrm{a}$ & $7,88 \mathrm{a}$ \\
\hline DMS & 0,25 & nd & 0,3319 & 0,29 \\
\hline \hline
\end{tabular}


Médias com letras em comum na mesma coluna indicam que as médias não têm diferença significativa entre si $(\mathrm{p}<0,05)$ pelo teste de Tukey.

DMS = Diferença mínima significativa.

nd $=$ Não difere.

\section{5- CONCLUSÃO}

Os produtos foram sensorialmente aceitos, indicando que a utilização do albedo do maracujá, apresentou-se como um ingrediente alternativo para substituição da pectina cítrica comercial (substância requerida para dar consistência ao doce de corte).

A aplicação da tecnologia gerada poderá beneficiar pequenos produtores, pelo melhor aproveitamento das matérias primas, bem como as pequenas agroindústrias familiares.

\section{RFERÊNCIAS BIBLIOGRÁFICAS}

ARANHA, F. Q.; SIMÕES, M. O. S. Determinação do teor de vitamina C (ácido ascórbico) na polpa de acerola (Malpighia Glaba L.), em João Pessoa, Paraíba. Higiene alimentar, 2003, n. 17, v. 17, p.45-53.

BRASIL, Ministério da Saúde - Agência Nacional de Vigilância Sanitária - ANVISA. Resolução- CCPANn ${ }^{\circ}$. 12, de 1978 disponível em: http://elegis.anvisa.gov.br/leisres/public/showact.php?mode=print_version\&id=16216, acesso em 07/01/2008.

CHOUDHRY, M.M.; COSTA, T. S. da; ARAÚJO, J.L.P. Goiaba: Pós-colheita. In:Agronegócio da Goiaba.p. 9-15. EMBRAPA Informação Tecnológica. 45p. il.; (Frutas do Brasil, 19). 2001.

CARNEIRO, Lucia C.; CAIRES, E.O.; GOULART, C.; ALVES, C.J.; SILVA, M. A. P. Caracteristicas de geléia de limão obtida por processo convencional e não convencional. Resumos do XIX Congresso Brasileiro de Ciência e Tecnologia de Alimentos CBCTA, Recife, setembro, 2004.

CARNEIRO, Lucia C.; MACHADO, Simone S.; CARDOSO, Joeber A. B. ALVES, Cleide J.; SANTOS, Wandressa L. dos. NASCIMENTO, Renata. Avaliação físico-quimica e sensorial de doce de pasta a base de polpa de tamarindo (Tamarindus indica), polpa resíduo de cenoura (Daucus carota) e albedo do maracujá amarelo (Passiflora war, edulis Flavicarpa), Resumos da II SECETEC - semana de Ciência e Tecnologia - CEFETRV, Rio Verde-GO, outubro, 2005.

COSTA, Ambrósia Maria Nobre Maia; CHAVES, Claudene Guerreiro; FREITAS, Rafaella Martins de; ROCHA, Érica Milô de Freitas Felipe; MOURA, Leyna Bezerra de; MARQUES, Luciana Façanha; COSTA, Ticiana Leite; MOURA, Rodrigo Leite. ANÁLISE SENSORIAL DE DOCE EM CALDA A PARTIR DA CASCA DO MARACUJÁ AMARELO COM DIFERENTES CONCENTRAÇÕES DE AÇÚCAR, III JORNADA NACIONAL DA AGROINDÚSTRIA, Bananeiras, ago. 2008. ISSn 19801122. 
EMBRAPA, Iniciando um pequeno grande negócio agroindustrial: Frutas em calda, geléias e doces, Brasília, Embrapa, Sebrae, 2003 (Série Agronegócios) Parte 1: Processo de produção, p. 10-84.

INSTITUTO ADOLFO LUTZ. Normas Analíticas do Instituto Adolfo Lutz. Métodos químicos e físicos para análise de alimentos, v. 1, 3. ed. São Paulo: Inst. Adolfo Lutz, 1985. 533p.

JACKIX, M. H. Geléias e Doces em massa. In: JACKIX, M. H. Doces. Geléias e frutas em calda (Teórico e Prático). Campinas, Ed. UNICAMP, 1988, Campinas: Ícone, 1988. Cap. 4, p.85-158.

TOCCHINI, Rogério P.; NISIDA, Alba L. A. C.; HASHIZUME, Takuo; MEDINA, Júlio C.; TURATTI, Jaane M. Processamento: produtos, caracterização e utilização. In: Maracujá - cultura, matéria-prima e aspectos econômicos. et. al., 1995). Campinas, ITAL, 1995, p. 161-195.

URBANO, Matsuura F. C. A. Estudo do Albedo do maracujá e de seu aproveitamento em barras de Cereais. 2000. Tese (Doutorado em Tecnologia de Alimentos - UNICAMP, Campinas, 2003.

Organização das Nações Unidas para Agricultura e Alimentação disponível em: HTTP://www.iac.sp.gov.br/OAgronomico/58/Goiaba\%20no\%20mundo.pdf. Acesso em 17 de agosto de 2009. 